\title{
Does a shorter length of hospital stay affect the outcome and costs of hysterectomy in southern England?
}

\author{
Aileen Clarke, Pam Rowe, Nick Black
}

\begin{abstract}
Study objective - To see whether a shorter postoperative length of stay (LOS) for a major procedure, abdominal hysterectomy for benign conditions, was associated with health outcome, the use of formal and lay care after discharge, cost, and satisfaction.
\end{abstract}

Design - Prospective cohort study.

Setting - Three hospitals in London and three in Hertfordshire and Bedfordshire. Patients - A total of 363 women undergoing total abdominal hysterectomy with or without oophorectomy: 112 with a short postoperative LOS (five days or less) and 251 with a standard LOS (six days or more).

Main outcome measures - Wound infection within 10 days and six weeks; change in general health status. (Nottingham health profile) after six weeks; general health and change in social activity (lifestyle index) three months after surgery. Mean cost difference for hospitals, use of formal and lay care after discharge, and patient satisfaction.

Results - Short LOS was associated with benefits: a lower risk of wound infection in the first 10 days (odds ratio $0.44 ; p=$ 0.03 ) and no deterioration in physical mobility (measured using the NHP) after six weeks - and with adverse outcomes: constipation six weeks later (OR $0.48 ; p<0.001$ ) and moderate or severe urinary symptoms six weeks (OR 0.69; p<0.004) and three months (OR 0.65; p<0.008) later. On multivariate analysis, the only outcome to remain significantly associated with LOS was physical mobility after six weeks $(p=$ $0.024)$. There was no significant difference between short and standard stay women as regards their use of formal or lay care after discharge from hospital. The mean cost of hospital care was $£ 251$ (in 1992) less for short than for standard stay patients. Most women ( $73 \%$ at six weeks) felt their LOS was appropriate. Short stay women were more likely to feel it was too short, though the difference was not statistically significant.

Conclusions - Short postoperative stays do not seem to be associated with any adverse outcomes and result in modest financial saving to the health service.
There is potential for greater use of early discharge.

\section{(f Epidemiol Community Health 1996;50:545-550)}

Length of hospital stay (LOS) has fallen in all countries over the past 20 years. Despite widespread professional and public concern about possible adverse effects of shorter LOS on the outcome of care, there have been few studies conducted. ${ }^{1-3}$ Only five randomised controlled trials have been reported and these have been confined to minor elective surgical procedures - hernia repair, varicose vein ligation, and haemorrhoidectomy. No significant differences in outcome between early and late discharge groups were found ${ }^{4-8}$ but complication rates were higher in the early discharge groups ( $15 \%$ versus $8 \%$ ).

Using observational data, a strong association between LOS and mortality, having adjusted for case mix, has been found but this association may have arisen because patients discharged earlier may die outside hospital. ${ }^{9}$ More recently, variations in LOS between six US hospitals were found not to be associated with outcome even after adjusting for case mix differences. ${ }^{10}$

It has also been found in some studies that shorter LOS is associated with lower patient satisfaction with care, ${ }^{11}$ though other studies have shown the opposite. ${ }^{10}$ In general, it seems that patients appreciate their time in hospital regardless of their $\operatorname{LOS}^{81213}$

A potential advantage of shorter LOS often suggested is increased efficiency. Economic benefits have, however, been found to be small ${ }^{1}$ since reduction in length of stay rarely represents a reduction in the intensity of services provided. ${ }^{14}$ Marginal savings do not necessarily translate into reductions in average costs. ${ }^{15}$ In addition, as LOS falls other inputs such as complex investigations may increase. Finally, there have been concerns expressed that reductions in LOS shift costs from hospitals to patients and their lay carers, though studies have failed to show such an association..$^{112}$

In summary, the few studies that have been performed have shown no important effect of reduction of LOS on health outcome, patient satisfaction, or costs of care. Despite this, concerns remain. Also, the studies that have been conducted in the UK have largely been restricted to minor surgical procedures. The aims 
Table 1 Questions included in lifestyle index

Questions:

To what extent do you Sex life has been affected by your symptoms/operation? feel your:

Symptoms/health interfere with your social life?

Symptoms/health interfere with your relationship with your partner? Symptoms/health interfere with your relationship with your children? Symptoms/health interfere with your holidays and outings?

In the past month, how Reduce your normal household activities? many days has your Have time off work? meany days

In the past week:

How many days have you felt like staying in and around the house because of your health?

How often have you spent any time resting during the day?

of this study were to see whether shorter LOS for a major procedure, abdominal hysterectomy for benign conditions, was associated with health outcome, the use of formal and lay care after discharge, cost, and satisfaction.

\section{Methods \\ DATA COLLECTION}

Between April 1991 and June 1992, all women undergoing total abdominal hysterectomy for benign conditions in six hospitals in North West Thames Health Region (three in London, three in Hertfordshire and Bedfordshire) were invited to participate in a prospective cohort study. Women were excluded if they were unable to read and understand English or were undergoing surgery for malignancy (including cervical intraepithelial neoplasia grade III). Of 704 eligible women, 495 (70.3\%) were invited to participate. Altogether $366(52.0 \%)$ agreed and completed a preoperative questionnaire, handed to them on the ward by a member of the nursing staff. Mailed questionnaires were completed by 349 (95.4\%) women at 10 days, $318(86.9 \%)$ at six weeks, and $300(82.0 \%)$ at three months.

The questionnaires for patients were based on evidence from published studies and from interviews with 35 women, some of whom were awaiting surgery and others who had recently undergone a hysterectomy. The preoperative questionnaire included sociodemographic variables (age, housing tenure, age of completion of education, employment status), clinical factors (symptom severity, co-morbidity, suspected pathology), general health status (measured using global questions and the Nottingham health profile $(\mathrm{NHP})^{16}$ ), psychological health, and quality of life.

Many of the same topics were included in the three questionnaires. In addition, 10 days after surgery women were asked about their experience in hospital (including care and discharge arrangements), the immediate effects of surgery, any adverse outcomes (including wound problems and other complications), and their use of formal and lay care after discharge. Lay care was estimated by asking patients how long a carer had taken time off work to look after them. These topics were repeated six weeks and three months after surgery except for the questions on hospital stay.

Four indices were constructed to enable data to be summarised. ${ }^{17}$ Questions on three aspects of menorrhagia (days of bleeding, amount of bleeding, days of analgesia use) were used to construct a preoperative symptom index. Each aspect was rated from 0 (least severe) to 4 (most severe). The summed totals were grouped into: $0=$ none,$\quad 1-3=$ mild, $4-6=$ moderate, and $7-12=$ severe. A comorbidity index was constructed from questions on cardiovascular, respiratory, neurological and other diseases which classified patients into four categories: none, mild, moderate, severe.

An index of activities of daily living (ADL) was constructed from seven questions scored from $0=$ experience no difficulty, to $2=$ great difficulty. A lifestyle index was constructed from nine questions about social activity (table 1). Responses were scored according to the degree to which the woman's lifestyle was affected by her condition: not at all $=0$; a little $=$ 1 ; somewhat $=2$; considerably $=3$; a lot $=4$.

Information on length of stay, use of prophylactic antibiotics, operative procedure, grade of surgeon, complicating features of surgery, operation duration, and any in-hospital complications was extracted from the case notes of $363(97 \%)$ patients between 10 days and six weeks after surgery by members of the research team with a medical or nursing background (AC,SM, KH). More details of the clinical management of the patients have been reported elsewhere. ${ }^{18}$

To determine the staffing costs of an additional day in hospital, 12 patients in three wards kept diaries which detailed the occasions and times at which they received medical, nursing, and physiotherapy care during their last complete 24 hours in hospital before being discharged. Estimates of the average times typically taken to perform activities were made by two of the study staff (AC and SM). Patient contact time as a proportion of total working time has been found to be $50 \%$ for nurses and $42 \%$ for junior doctors during the working day, ${ }^{1920}$ and was assumed to be $50 \%$ for physiotherapists. Estimated non-contact times were added to contact times, to give total time devoted to the patient, and was costed using routinely available salary data. Routine data on capital costs and the costs of hotel services were obtained from four of the six hospitals. Costs were averaged to give mean hotel and capital costs per patient day. From these, the overall cost of a final day in hospital was calculated.

At the time of the study, the standard length of stay was six days or more. A "short stay" group was therefore defined as having a stay of less than six days and the rest were included in a "standard stay" group. Power calculations suggested that a sample size of 360 (with a minimum of 120 in each category) would allow the detection of a $15 \%$ difference between short and standard stay groups for an outcome with a prevalence of $20 \%$ in the standard stay group $(80 \%$ power, $\mathrm{p}<0.05)$.

\section{OUTCOME VARIABLES}

Details of the outcome of surgery have been reported elsewhere. ${ }^{17}$ Initially, the relationship of LOS with six clinical and ten psychosocial outcomes was considered by calculating odds ratios. 
Table 2 Possible patient factors predictive of outcome and odds ratios (95\% confidence intervals) of a short length of postoperative stay

\begin{tabular}{|c|c|c|}
\hline Predictor & No (\%) & Odds ratio $(95 \%$ CI) \\
\hline \multicolumn{3}{|l|}{ Age (y) } \\
\hline 50 or less & $321(89.7)$ & $2.01(0.81,4.62)$ \\
\hline 51 or more & $37(10.3)$ & 1.00 \\
\hline \multirow{2}{*}{\multicolumn{3}{|c|}{ Housing tenure }} \\
\hline & & \\
\hline Tenant & $121(33.6)$ & $1.79(1.09,2.93)$ \\
\hline Owner occupier & $239(66.4)$ & 1.00 \\
\hline Missing & 6 & \\
\hline \multicolumn{3}{|l|}{ Employment status } \\
\hline Part time/not working & $195(54.8)$ & $1.54(0.95,2.51)$ \\
\hline Full time & $161(45.2)$ & 1.00 \\
\hline Missing & 10 & \\
\hline \multicolumn{3}{|c|}{ Age (y) completed full time education } \\
\hline 16 or less & $220(61.4)$ & $1.00(0.61,1.63)$ \\
\hline 17 or more & $138(38.6)$ & 1.00 \\
\hline Missing & 8 & \\
\hline \multicolumn{3}{|l|}{ Symptom severity } \\
\hline Severe & $80(21.9)$ & $0.62(0.30,1.30)$ \\
\hline Moderate & $194(53.2)$ & $1.09(0.62,1.93)$ \\
\hline Mild/none & $91(24.9)$ & 1.00 \\
\hline Missing & 1 & \\
\hline \multicolumn{3}{|l|}{ Suspected pathology } \\
\hline Dysfunctional bleeding & $178(50.6)$ & $0.57(0.23,1.43)$ \\
\hline Fibroids & $147(41.8)$ & $0.62(0.25,1.58)$ \\
\hline Endometriosis & $27(7.7)$ & 1.00 \\
\hline Other & 13 & \\
\hline Missing & 1 & \\
\hline \multicolumn{3}{|c|}{ Complicating features of surgery } \\
\hline Absent & $213(58.8)$ & $1.41(0.87,2.31)$ \\
\hline Present & $149(41.2)$ & 1.00 \\
\hline Missing & 1 & \\
\hline \multicolumn{3}{|l|}{ Comorbitity } \\
\hline Moderate/severe & $38(10.4)$ & $1.24(0.5,2.67)$ \\
\hline None/mild & $327(89.6)$ & 1.00 \\
\hline Missing & 1 & \\
\hline
\end{tabular}

Information obtained from patients $(\mathrm{n}=366)$ except for complicating features of surgery which was obtained from case notes $(n=363)$

Table 3 Possible health service factors predictive of outcome and odds ratios $(95 \%$ confidence intervals) of a short length of postoperative stay

\begin{tabular}{lrr}
\hline Predictor & No (\%) & Odds ratio (95\% CI) \\
\hline Hospital & & \\
2 & $59(16.1)$ & $13.50(3.99,57.30)$ \\
3 & $45(12.3)$ & $6.80(1.90,29.90)$ \\
5 & $80(21.9)$ & $5.20(1.60,21.80)$ \\
6 & $46(12.6)$ & $3.30(0.87,15.04)$ \\
1 & $95(26.0)$ & $1.60(0.45,7.10)$ \\
4 & $41(11.2)$ & 1.00 \\
Surgical procedure & $174(48.5)$ & $1.78(1.10,2.89)$ \\
Hysterectomy & $185(51.5)$ & 1.00 \\
Hysterectomy and oophorectomy & 4 & \\
Missing & $223(63.9)$ & $1.46(0.86,2.46)$ \\
Grade of surgeon & $126(36.1)$ & 1.00 \\
Junior & 14 & \\
Consultant & $132(38.3)$ & $1.20(0.73,1.97)$ \\
Missing & $213(61.7)$ & 1.00 \\
Duration of operation & 18 & \\
Less than 1 h & & \\
1 h or more & $262(76.2)$ & $1.30(0.72,2.34)$ \\
Missing & $82(23.8)$ & 1.00 \\
In-hospital complications* & 5 & \\
Absent & & \\
Present & $244(69.3)$ & $1.03(0.61,1.74)$ \\
Missing & $108(30.7)$ & 1.00 \\
Prophylactic antibiotics & 11 & \\
Given & $112(30.8)$ & \\
Not given & $251(69.2)$ & \\
Missing. & $292(86.4)$ & $1.50(0.69,3.26)$ \\
Length of postoperative stay & $46(13.6)$ & 1.00 \\
5 d or less & 11 & \\
6 or more & & \\
Hospital discharge & & \\
No difficulties & & \\
Difficulties & & \\
Missing & & \\
\hline Excluding wound infections & & \\
\hline & &
\end{tabular}

* Excluding wound infections.

Information on: surgical procedure, grade of surgeon, duration of operation, prophylactic antibiotics, and length of stay obtained from case notes $(n=363)$; in-hospital complications and hospital discharge obtained from 10 day postal questionnaire $(n=349)$.

PREDICTOR VARIABLES

The seven patient and eight health service factors (other than length of stay) which were considered as possible predictor variables of outcome are listed in tables 2 and 3, together
Table 4 Comparison of recruited and non-recruited patients undergoing hysterectomy in the study period

\begin{tabular}{lcc}
\hline & $\begin{array}{l}\text { Non-recruited } \\
(n=338)\end{array}$ & $\begin{array}{c}\text { Recruited } \\
(n=366)\end{array}$ \\
\hline Median age (y) & 44 & 42 \\
Mean (95\% CI) age (y) & $43.7(43.0,44.5)$ & $42.3(41.5,43.1)$ \\
LOS (median) (d) & 7.00 & 7.00 \\
Principal indication (\%): & & \\
Fibroids & 36.7 & 40.1 \\
Endometriosis & 12.1 & 7.4 \\
Dysfunctional bleeding & 56.0 & 48.6 \\
Other & 2.7 & 3.8 \\
Oophorectomy (\%): & 49.1 & 43.6 \\
Bilateral & 4.5 & 7.1 \\
Unilateral & & \\
\hline
\end{tabular}

with the distribution of each variable (patient numbers and percentages within each category).

\section{STATISTICAL METHODS}

In order to examine whether possible predictor variables were confounding the observed relationship between LOS and outcome, the odds of a short compared with a standard LOS were calculated for patients within each of the 15 predictor categories (taking the risk in the worst predictor category as 1.00 ). The odds ratios of an adverse outcome associated with a short length of stay were calculated for different outcomes. Ten outcomes, representing a range of medical and social measures, were selected for investigation of possible confounding. Adjustment for known or potential confounding variables was undertaken using multiple regression (GLIM for continuous variables and logistic regression using $E G R E T$ for binary variables). For each model, relationships between outcome variables and LOS were explored while controlling for possible confounding factors by entering them first into the model. Initially all 15 possible predictor variables were included, though in the final model only those that made a significant impact or were plausible were included.

\section{Results}

Recruitment and response bias. There were no significant differences between participants and non-participants as regards age, length of stay, diagnosis, and whether or not oophorectomy was undertaken (table 4). Responders at three months did not differ significantly from nonresponders with regard to age, type of operation, symptom severity, co-morbidity, or LOS.

\section{LOS AND HEALTH OUTCOMES: UNIVARIATE}

\section{ANALYSES}

Of the 363 (99\%) women for whom LOS was known, $112(30.6 \%)$ stayed 5 days or less, 160 $(44.0 \%)$ stayed 6 days, $46(12.6 \%)$ stayed 7 days and $45(12.2 \%)$ stayed 8 days or more. Of the six clinical outcomes measured, LOS was significantly associated with only three (table 5). Women discharged early were less likely to: have a wound infection in the first ten days $(p=0.03)$; suffer from constipation six weeks later $(p<0.001)$; and complain of moderate or severe urinary symptoms six weeks 
Table 5 Odds ratios (95\% confidence intervals) of an adverse clinical outcome associated with a short length of stay (LOS)

\begin{tabular}{lccc}
\hline Outcome & Short LOS (\%) & Standard LOS (\%) & Odds ratio (95\% CI) \\
\hline Analgesia use & & & \\
At 10d & $64(61.0)$ & $173(71.5)$ & $0.85(0.72,1.01)$ \\
At 6 wk & $18(19.8)$ & $26(13.9)$ & $1.42(0.82,2.46)$ \\
At 3 mth & $6(8.2)$ & $13(7.7)$ & $1.07(0.42,2.70)$ \\
Urinary tract infection & $14(13.3)$ & $42(17.6)$ & $0.76(0.43,1.33)$ \\
$\quad$ Within 10d & $71(67.6)$ & $172(71.1)$ & $0.95(0.81,1.11)$ \\
Moderate/severe urinary symptoms & $41(40.2)$ & $125(58.4)$ & $0.69(0.53,0.89)$ \\
At 10d & $30(32.3)$ & $102(49.5)$ & $0.65(0.47,0.90)$ \\
At 6 wk & $42(40.4)$ & $119(50.0)$ & $0.81(0.62,1.05)$ \\
At 3 mth & $18(17.6)$ & $79(37.1)$ & $0.48(0.30,0.75)$ \\
Constipation & $10(10.8)$ & $37(18.1)$ & $0.59(0.30,1.01)$ \\
At 10d & $8(7.6)$ & $41(17.2)$ & $0.44(0.21,0.91)$ \\
At 6 wk & $13(13.0)$ & $37(17.7)$ & $0.73(0.41,1.32)$ \\
At 3 mth & $13(14.0)$ & $40(19.5)$ & $0.72(0.40,1.27)$ \\
Wound infection & $5(5.5)$ & $17(8.3)$ & $0.66(0.25,1.74)$ \\
Within 10d & &
\end{tabular}

Table 6 Odds ratios (95\% confidence intervals) of an adverse social or psychological outcome associated with a short length of stay (LOS)

\begin{tabular}{|c|c|c|c|}
\hline Outcome & Short LOS (\%) & Standard LOS (\%) & Odds ratio $(95 \%$ CI) \\
\hline \multicolumn{4}{|l|}{ Irritable } \\
\hline At $10 \mathrm{~d}$ & $6(8.0)$ & $22(12.6)$ & $0.64(0.27,1.51)$ \\
\hline At $6 \mathrm{wk}$ & $15(17.6)$ & $34(19.9)$ & $0.88(0.51,1.54)$ \\
\hline At $3 \mathrm{mth}$ & $10(11.8)$ & $38(19.9)$ & $0.59(0.31,1.13)$ \\
\hline \multicolumn{4}{|c|}{ Fair/poor general health } \\
\hline At $10 \mathrm{~d}$ & $27(26.2)$ & $76(31.9)$ & $0.82(0.57,1.19)$ \\
\hline At $6 \mathrm{wk}$ & $15(14.7)$ & $40(18.8)$ & $0.78(0.45,1.35)$ \\
\hline At $3 \mathrm{mth}$ & $13(14.3)$ & $29(14.1)$ & $1.01(0.55,1.86)$ \\
\hline \multicolumn{4}{|l|}{ Depressed } \\
\hline At $10 \mathrm{~d}$ & $53(53.0)$ & $133(56.6)$ & $0.94(0.76,1.16)$ \\
\hline At $6 \mathrm{wk}$ & $34(35.8)$ & 77 (39.9) & $0.89(0.65,1.24)$ \\
\hline At $3 \mathrm{mth}$ & $15(17.4)$ & $45(23.4)$ & $0.74(0.44,1.26)$ \\
\hline \multicolumn{4}{|c|}{ Quality of life same or worse } \\
\hline At $10 \mathrm{~d}$ & $56(54.9)$ & $130(54.6)$ & $1.01(0.81,1.24)$ \\
\hline At $6 \mathrm{wk}$ & $35(34.7)$ & $58(27.2)$ & $1.27(0.90,1.80)$ \\
\hline At $3 \mathrm{mth}$ & $20(21.7)$ & 39 (18.9) & $1.15(0.71,1.86)$ \\
\hline \multicolumn{4}{|c|}{ Enjoyment of sex only fair or poor } \\
\hline At $3 \mathrm{mth}$ & $29(36.3)$ & $50(31.6)$ & $1.15(0.79,1.66)$ \\
\hline \multicolumn{4}{|c|}{ Five hours or less housework per week } \\
\hline At $6 \mathrm{wk}$ & $65(65.0)$ & $158(75.6)$ & $0.86(0.73,1.01)$ \\
\hline At $3 \mathrm{mth}$ & $50(54.3)$ & $112(54.9)$ & $0.99(0.79,1.24)$ \\
\hline \multicolumn{4}{|c|}{ Not working outside the home } \\
\hline By 6 wk & $68(93.1)$ & $151(95.6)$ & $0.97(0.91,1.05)$ \\
\hline By $3 \mathrm{mth}$ & $32(49.2)$ & $68(43.9)$ & $1.12(0.83,1.52)$ \\
\hline
\end{tabular}

Table 7 Mean scores (95\% confidence intervals) for activities of daily living (ADL), Nottinham health profile (NHP), and lifestyle index for short and standard length of stay (LOS) women

\begin{tabular}{lcc}
\hline Outcome & Short LOS & Standard LOS \\
\hline Change in ADL by 6 wk & $-1.0(-1.5,-0.5)$ & $-1.3(-1.7,-1.0)$ \\
Change in NHP by 6 wk & $27.7(18.9,36.5)$ & $20.2(13.9,26.5)$ \\
Energy & $10.4(4.9,16.0)$ & $7.4(3.2,11.5)$ \\
Pain & $18.3(13.7,22.9)$ & $17.9(14.6,21.2)$ \\
Emotional reactions & $13.2(7.3,19.1)$ & $9.2(4.6,13.9)$ \\
Sleep & $3.7(-0.9,8.3)$ & $2.4(-0.3,5.1)$ \\
Social isolation & $-0.5(-4.1,3.1)$ & $-6.1(-8.9,-3.3)$ \\
Physical mobility & $28.1(22.9,33.2)$ & $25.0(21.3,28.7)$ \\
\hline
\end{tabular}

Table 8 Odds ratio (95\% confidence intervals) of an adverse outcome associated with a standard length stay having adjusted for known and potential confounders

\begin{tabular}{lll}
\hline Outcome & $\begin{array}{l}\text { Odds ratio for outcome in standard } \\
\text { compared with short stay group }\end{array}$ & $(95 \% \mathrm{CI})$ \\
\hline Wound infection & & \\
Within $10 \mathrm{~d}$ & 2.27 & $(0.98,5.265)$ \\
Within 6 wk & 2.05 & $(0.97,4.324)$ \\
General health fair or poor at 3 mth & 1.18 & $(0.55,2.520)$ \\
& $\begin{array}{l}\text { Change in score for standard } \\
\text { compared with short stay group }\end{array}$ & $(-11.16,1.86)$ \\
Change in lifestyle index by 3 mth* & -4.65 & $(-20.05,2.49)$ \\
Change in NHP by 6 wk* & -8.78 & $(-11.52,3.27)$ \\
Energy & -4.12 & $(-6.54,5.74)$ \\
Pain & -0.40 & $(-13.57,3.28)$ \\
Emotional reactions & -5.15 & $(-8.50,2.06)$ \\
Sleep & -3.22 & $(-11.61,-0.87)$ \\
Social isolation & -6.24 & \\
Physical mobility & &
\end{tabular}

* Negative change indicates less improvement in standard stay group.

NHP $=$ Nottingham health profile $(\mathrm{p}<0.004)$ and three months $(\mathrm{p}<0.008)$ later. LOS was not significantly associated with any of the 10 psychosocial outcome variables examined with the exception of the physical mobility component of the NHP which had deteriorated in women who had a long stay (tables 6 and 7 ).

\section{LOS AND HEALTH OUTCOMES: MULTIVARIATE} ANALYSES

Only three potential confounding factors were found to be statistically significantly associated with LOS at the $5 \%$ level - housing tenure, hospital and surgical procedure (tables 2 and 3 ). As significant confounding can occur even if there is no statistically significant association between predictors and LOS or outcomes, the multivariate analysis considered all known or potential factors for which data were available. Such adjustment made little difference to the associations already found (table 8). The prevalence of wound infections within 10 days was higher for women with a standard LOS, although this difference did not quite reach statistical significance at the $5 \%$ level.

Three months after surgery there was no significant relationship between LOS and the likelihood of women either reporting their general health as being only fair or poor or the extent of the change in their lifestyle index score. The only statistically significant finding with the NHP six weeks after surgery was that physical mobility had deteriorated among the standard stay women whereas it was largely unchanged in the short stay group $(\mathrm{p}=0.02)$. Such a small difference (about 6\%), however, is of little clinical or social significance.

The one variable that was significant in many of the final multivariate models (exceptions being for wound infection and general health) was preoperative symptom severity. Both moderate and severe symptoms were positively associated with greater improvement in health (lifestyle index and all dimensions of the NHP except physical mobility) when adjustments for other confounding factors were made.

USE OF FORMAL AND LAY CARE AFTER DISCHARGE

About $80 \%$ of patients saw their GP within three months of surgery (table 9). The proportion did not differ significantly between the short and standard stay groups. Forty seven per cent of the patients had a carer who took some time away from work to look after them. The mean time taken off work by lay carers was similar for the two groups.

COST OF FINAL DAY IN HOSPITAL

The times devoted to various types of professional care during the last 24 hours in hospital are shown in table 10 . The ranges for each component of hospital cost were wide (table 11) reflecting variation between hospitals in staff contact time. Staffing costs, as a proportion of overall costs, were lower than generally found because they were measured at 
Table 9 Amount of formal and lay care following surgery in relation to length of postoperative hospital stay

\begin{tabular}{lcll}
\hline & Short stay & Standard stay & Relative risk for short stay \\
\hline GP consultation & & & \\
Within 10 d & $41.9 \%$ & $45.4 \%$ & $0.92(0.71,1.20)$ \\
Within 6 wk & $66.6 \%$ & $74.7 \%$ & $0.89(0.76,1.04)$ \\
Within 3 mth & $79.5 \%$ & $83.7 \%$ & $0.95(0.85,1.06)$ \\
Mean number of days lay & & & \\
carer took off work (95\% CI) & $9.9(7.0,12.9)$ & $10.6(9.1,12.1)$ & \\
\hline
\end{tabular}

Table 10 Staffing contact times and costs for the last 24 hours before hospital discharge

\begin{tabular}{lllll}
\hline Type of staff & $\begin{array}{l}\text { Mean contact time } \\
\text { min/d (range) }\end{array}$ & $\begin{array}{l}\text { Mean contact plus non- } \\
\text { contact time min/d (range) }\end{array}$ & $\begin{array}{l}\text { Cost/h } \\
(£)\end{array}$ & $\begin{array}{l}\text { Cost/d (range) } \\
(f)\end{array}$ \\
\hline Nurse & $85(15-177)$ & $170(30-354)$ & $8.50^{*}$ & $24.1(4.4-50.2)$ \\
Doctor & $18(0-42)$ & $28(0-60)$ & $18.66 \dagger$ & $8.8(0-18.7)$ \\
Physiotherapist & $4(0-20)$ & $8(0-40)$ & 11.00 & $1.5(0-7.3)$ \\
\hline
\end{tabular}

* Average cost per hour of midpoint salary scale for staff nurse and student nurse including London weighting.

† Average cost per hour (on-call hours included) of senior house officer, registrar, and senior registrar including inner London weighting.

Table 11 Total cost per patient for the last 24 hours before hospital discharge

\begin{tabular}{lcc}
\hline Category of cost & $\begin{array}{l}\text { Total cost per patient day } \\
(£) \text { (range) }\end{array}$ & $\begin{array}{l}\text { Percentage of } \\
\text { total cost }\end{array}$ \\
\hline Clinical staff & $34.4(4.4-76.2)$ & 24.6 \\
Hotel services & $90.9(53.9-127.0)$ & 65.0 \\
Capital & $14.5(6.0-26.5)$ & 10.4 \\
Total & $139.8(64.2-229.6)$ & 100 \\
\hline
\end{tabular}

Table 12 Women's views on appropriateness of postoperative length of stay

\begin{tabular}{llrl}
\hline & $\begin{array}{l}\text { Too long } \\
(\%)\end{array}$ & \multicolumn{1}{c}{$\begin{array}{l}\text { About right } \\
(\%)\end{array}$} & $\begin{array}{l}\text { Too short } \\
(\%)\end{array}$ \\
\hline Ten d (no) & & & \\
$\quad$ Short stay (104) & $4(3.8)$ & $79(75.2)$ & $21(20.0)$ \\
$\quad \begin{array}{l}\text { Standard stay (236) } \\
8(3.3)\end{array}$ & $197(81.4)$ & $31(12.8)$ \\
Six wk (no) & $3(2.9)$ & $70(68.6)$ & $28(27.5)$ \\
$\quad$ Short stay (101) & $7(3.3)$ & $160(74.8)$ & $44(20.6)$ \\
$\quad$ Standard stay (211) & $7(3.0)$ & \\
\hline$\chi^{2} 10 \mathrm{~d}=2.89, \mathrm{p}>0.1 ; 6 \mathrm{wk}=1.82, \mathrm{p}>0.1$.
\end{tabular}

the low dependency end of the hospital stay. Overall, the cost for the final day spent in hospital was found to be $£ 140$ (range $£ 64$ $£ 230$ ) in 1992. Thus, the mean difference in hospital cost between standard stay (mean of 6.65) and short stay (4.86) patients was $£ 251$ (range $£ 115-£ 412$ ).

\section{WOMEN'S VIEWS OF THE LENGTH OF THEIR STAY}

Most women felt their length of stay was about right (table 12). Six weeks after surgery, however, nearly a quarter believed that it had been too short. Women who had a short stay were more likely to feel it was too short, though the difference was not significant (relative risk 1.54 ( $95 \%$ confidence interval $0.94,2.53)$ at 10 days; $1.32(0.83,1.95)$ at 6 weeks). Reasons given for feeling their stay was too short included a sense of vulnerability stemming from a perceived lack of professional advice or support in the community. Specific concerns included being discharged: before symptoms such as pain or bowel disturbance were adequately under control; while developing an infection; with an in-dwelling catheter; and only half an hour after wound staples had been removed.
Such concerns were heightened by a lack of information on what to expect in the first few days after they returned home.

Women rarely felt themselves to be active partners in the discharge decision and many commented on their enforced reliance on doctors, on the timing of ward rounds and the sense of helplessness that this engendered. Few women, however, thought that administrative reasons had curtailed their hospital stay. Any lack of beds, if apparent to nursing and medical staff, did not seem to have transmitted itself to the patients.

\section{Discussion}

Women staying in hospital for a shorter period (1.79 days less) after undergoing hysterectomy had a similar outcome to those staying longer. There was a financial saving for the hospital associated with a shorter LOS which did not appear to be transferred to the costs of additional care in the community either in terms of lay or formal care.

Before considering the implications of these findings, some methodological aspects of the study need to be discussed. Firstly, only $52 \%$ of eligible women in the six hospitals were recruited to the study. One reason for this was that nursing staff only invited about $70 \%$ of eligible women to participate, partly as an oversight and maybe also because recruiting women to the study involved them in additional work which disrupted their routine admitting practice. Despite only half the eligible women participating, those who were recruited did not differ from those not recruited in any substantial or significant way on any of the measures available from routine data. Recruitment is not thought therefore to have introduced any significant bias. Secondly, once women had agreed to take part, their response rates to the mailed questionnaires were high, with no evidence of any responder bias even three months after surgery.

A third concern is that of observer bias. Given that the women participating were not informed of the LOS hypothesis being tested, it is unlikely that they could have introduced any bias. The study staff who extracted data from the case notes could have done so, though the clinical variables they measured (procedure, grade of surgeon, duration of operation, prophylactic antibiotics, LOS, complicating features of surgery) are less vulnerable to observer bias.

The final methodological concern is the possibility of a survivor effect resulting from women with good (or adverse) outcomes progressively dropping out of the responding groups. In practice, the survival proportions were similar for both short and standard LOS groups at each of the three follow ups. Assuming the factors that influence response are not related to LOS, then any bias due to a survivor effect would affect both LOS groups in a similar way.

What are the implications of these findings for health services? Could all women safely be discharged after a short stay in hospital? Before 
answering this, it is important to recognise that the study employed an observational or nonexperimental design. In other words, allocation of the patients to either the short or standard stay groups was made by the hospitals. The fact that we found few differences in outcomes between the two groups might mean that women were being appropriately assigned to the correct LOS. It is possible that all those women who could safely tolerate a short stay were already being discharged early and that women in the standard stay group would have suffered if sent home sooner. In other words, short stay is safe and acceptable but this strategy is already being fully exploited by the hospitals. If this were true, then the implication of this study would be that hospitals should not seek to send more women home early. If this were not true, then hospitals could safely be discharging more women after only four or five days (or possibly less).

The question as to which interpretation is correct can be answered by considering what is known about the determinants of LOS. A separate multivariate analysis was undertaken and confirmed that short LOS was independently associated with only three of the 15 factors examined in this paper: being a tenant rather than an owner-occupier (odds ratio of short stay, OR: 1.83 (95\% confidence interval 1.04,23), not undergoing an oophorectomy with hysterectomy (OR: 2.41 (1.38, 4.24); and hospital of treatment (as compared with hospital 4: hospital 5, OR 7.51 (2.25, 25.07) hospital 3, OR $8.80(2.44,31.73)$, and hospital 2, OR $14.35(4.16,49.51)$. Overall differences between hospitals' mean were also confirmed (ANOVA $(\mathrm{F}=5.4359 \mathrm{p}<0.001)$ ). Thus, despite adjustment for a number of relevant patient variables including age, age of completion of education, diagnosis and comorbidity, differences between hospitals' length were confirmed. The only independent association between a socioeconomic variable found was counter-intuitive (a significant association between tenancy (not owning one's own home) and shorter LOS).

It is clear from these findings that one of the most important independent determinants of LOS was the hospital of treatment. This is strong support for the notion that more women could safely be discharged earlier without any detrimental effect to their health or their need for post-discharge care.
It is of course unclear the extent to which these results can be extrapolated to other major elective surgery let alone emergency admissions and medical conditions. Similar studies of other patient groups are needed to see how generalisable these findings are. Meanwhile, the results of this study provide support for policies to reduce length of stay.

Karen Howle and Sarah Mott assisted in the collection and processing of data and Angela Coulter, Jennifer Roberts, Charles Normand, Colin Sanderson and Mike Pawson kindly advised on particular aspects of study design and analysis. We would on particular aspects of study design and analysis. We would
like to thank the women, nursing staff and gynaecologists who like to thank the women, nursing staff and gynaecologists who took part. The work was supported by
Locally Organised Research Scheme.

1 Office of Technology Assessment. Variations in hospital length of stay: their relationship to health outcomes. Health Technology Case Study 24. Washington, DC: US Congress, OTA-HCS-23, August 1983.

2 McPherson K. Length of stay and health outcome. BMF 1984;288: $1854-55$.

3 Morgan M. Variations in length of stay at district level. In: Ham C ed. Health care variations. London, King's Fund Institute, 1988. Research Report No 2.

4 Burns LR, Wholey DR. The effects of patient, hospital, and physician characteristics on length of stay and mortality. Med Care 1991;29(3):251-71.

5 Ruckley CV. Day care and short stay surgery for hernia. $\mathrm{Br}$ 7 Surg 1978;65:1-4

6 Morris D, Ward A, Handyside A. Early discharge after hernia repair. Lancet 1968;i:681-85.

7 Russell I, Fell M, Devlin HB, et al. Day care surgery for hernias and haemorrhoids. Lancet 1977;i:844-47.

8 Adler MW, Waller JJ, Creese A, Thorne SC. Randomised controlled trial of early discharge for inguinal hernia and varicose veins. $\mathcal{f}$ Epidemiol Community Health 1978;32: $136-42$.

9 Flood AB, Ewy W, Scott R, Forrest WH, Brown BW. The relationship between intensity and duration of medical services and outcomes for hospitalised patients. Med Care 1979; XVII(11):1088-102.

10 Cleary PD, Greenfield S, Mulley AG, Pauker SG, Schroeder SA, Wexler L, McNeil BJ. Variations in length of stay and outcomes for six medical and surgical conditions in and outcomes for six medical and surgical conditions in

11 Adler MW, Waller JJ, Kasap HS, King C, Thorne SC. A randomised controlled trial of early discharge for inguinal hernia and varicose veins: some problems of methodology. Med Care 1974:XII(6):541-47.

12 Anderson P, Meara J, Broadhurst S, Attwood S, Timbrell $M$, Gatherer A. Use of hospital beds: a cohort study of admissions to a provincial teaching hospital. $B M \mathcal{F} 1988$; 297:910-12.

13 Audit Commission. Lying in wait: some reflections on the use of beds in district general teaching hospitals. London $\mathrm{HMSO}$ 1992 .

14 Jonsson B, Lindgren B. Five common fallacies in estimating the economic gains of early discharge. Soc Sci Med 1980; the econo $14: 27-33$.

15 Evans RG, Robinson GC. Surgical day care: measurements of the economic payoff. Can Med Assoc F 1989;123:873-88.

16 Hunt S, McKenna SP. The Nottingham health profile user's manual. Rev ed. Manchester: Galen Research and Consultancy, 1991.

17 Clarke A, Black NA, Rowe P, Mott S, Howle K. Indications for and outcomes of abdominal hysterectomy for benign disease. Br f Obstet Gynaecol 1995;102:611-20.

18 Black NA, Clarke A, Rowe P, Mott S, Howle K. A prospective cohort study of the clinical management of total abdominal hysterectomy for benign disease. 7 Obstet Gyn aecol 1995;15:394-400.

19 Reid N, Robinson G, Todd C. The quantity of nursing care on wards working 8-hour and 12-hour shifts. International fournal of Nursing Studies 1991;28:47-52.

20 Lothian Health Board. Survey of junior medical staff at the Royal Infirmary of Edinburgh. MEU Report 493. Edinburgh: Lothian Health Board, 1989. 